\title{
Medical Thoracoscopy in Daily Practice of Chest Medicine
}

\section{Levent Dalar}

Department of Pulmonary Medicine, İstanbul Bilim University School of Medicine, İstanbul, Turkey

Medical thoracoscopy, after being first introduce by Jacobaeus, continued to exist as a popular intervention during the years when tuberculosis was widespread in the western world. It lost popularity for many years when tuberculosis was under control; however, it has been increasingly used in the diagnosis of pleural diseases and also in the treatment for some special cases for the last 30 years. The common prevalence of interventional therapeutic methods for chest diseases has also played a role in the increasing use of this method. In this issue, I discuss the retrospective studies by Özgül et al. (1) in which they have shared their experiences of medical thoracoscopy. Apart from several studies conducted by Metintaş et al. and his large experience, the current case series is important for daily routin for pulmonary medicine although it has limited number of patients. There are no studies in our country other than this study, the semi-rigid thoracoscopic case series by Karasulu et al. (2) that included four patients, a 39-case series by Ekinci (3) whose consultant was Göksel Altınışık at Pamukkale University Faculty of Medicine, and the studies by Metintaş et al. Interventional bronchoscopy has gained great momentum in the last 15 years in our country. We are delighted to see that the number of centers as well as the number of publications that are published in succession in good journals has also increased. Although the medical thoracoscopy revived along with this acceleration, it cannot generally be applied in everyday clinical practice except in the above mentioned centers. The main reason for this is the perception that the fields of pulmonary diseases and thoracic surgeries are different. On the other hand, the borders of medical thoracoscopy have been drawn in international guidelines (4) and are mainly aimed at increasing the diagnostic effort, pleurodesis for malignant lesions, and pneumothorax in terms of treatment, occasionally limited with deloculation for empyema, which can be applied in an endoscopy room. Medical thoracoscopy is not comparable to video assisted thoracoscopic surgery (VATS). VATS is a technique performed by a thoracic surgeon that is entirely curative, is performed in an operating room, requires a double-lumen intubation, and includes a very broad spectrum of procedures. The main difference is that biopsy is performed with medical thoracoscopy and decortication is performed through VATS. However, the difficulties that may arise in the management of complications keep the away from this diagnostic approach. Among 37 patients in the series by Özgül et al. (1), one patient with poor general condition died because of hemothorax; however, while minor complications developed in five patients at a rate of $12.5 \%$, no major complication or death was observed in the study by Ekinci (3).

The diagnostic success was reported to be $97 \%$ in both studies.
In conclusion, medical thoracoscopy (pleuroscopy or thoracoscopy under local anesthesia) is an interventional approach that is different from the applications of thoracic surgeries and should be preferred over closed pleural biopsy; thus, it is an approach that significantly increases the diagnostic success. It has very low complication rates when it is performed by a trained practitioner and team. What the thoracic surgeons can do using VATS is far beyond the limits of the medical thoracoscopy, and neither approach is comparable with each other. As a result, I believe that this diagnostic success of the
The diagnostic success was reported to be $97 \%$ in both studies. 
centers that are well-trained, adequately equipped and interiorized institutionalized approaches for the management of complications will be an approach that will benefit patients and will promote the routine practice of chest medicine to be better.

\section{REFERENCES}

1. Özgül MA, Çetinkaya E, Tanrıverdi E, Çörtük M, Acat M, Gül Ş, et al. Diagnostic Value and Safety of Medical Thoracoscopy In Management of Exudative Pleural Effusion. Eurasian J Pulmonol 2016; 18: 139-42.
2. Karasulu AL, Dalar L, Altin S, Bakan ND, Sökücü SN. Semirigid thoracoscopy in the diagnosis of pleural effusion: first four cases in Turkey. Tuberk Toraks 2011; 59: 188-93. [CrossRef]

3. Ekinci A. Plevral sıvıların ayırıcı tanısında medikal torakoskopi (plöroskopi)'nin etkinliği ve güvenilirliği. Uzmanlık tezi. 2009.

4. Rahman NM, Ali NJ, Brown G, Chapman SJ, Davies RJO, Downer NJ, et al. Local anaesthetic thoracoscopy: British Thoracic Society Pleural Disease Guideline 2010. Thorax 2010; 65 (Suppl 2): ii54-60. [CrossRef] 